\title{
EXPERIMENTAL AND NUMERICAL STUDY ON THE FLEXURAL BEHAVIOR OF PRECAST LIGHT-WEIGHT CONCRETE SANDWICH
}

\author{
PANELS
}

\author{
J. Daniel Ronald Joseph ${ }^{1}$, J. Prabakar², P. Alagusundaramoorthy ${ }^{3}$ \\ ${ }^{I}$ Scientist, CSIR Structural Engineering Research Centre, CSIR Madras complex, Chennai, India \\ ${ }^{2}$ Senior Principal Scientist, CSIR Structural Engineering Research Centre, CSIR Madras complex, Chennai, India \\ ${ }^{3}$ Professor, Structural Engineering Laboratory, IIT Madras, Chennai, India \\ *Corresponding author: ronald.dany@gmail.com;
}

\begin{abstract}
Use of light-weight structural elements in buildings is becoming popular in the recent years. This paper presents the experimental and numerical studies carried out to understand the flexural behavior of prototype precast light-weight concrete sandwich panels under four-point bending. In the experimental study, two prototype panels were cast and tested. Transverse deflections of the panels were recorded during testing and the results are presented and discussed. Numerical studies were carried out using the general purpose finite element software ABAQUS. 8-noded linear brick element and 2-noded linear truss element were used to model the wythes and mesh reinforcements, respectively. Saenz model is used to model the behavior of concrete in compression. It is observed from the tests that, the panels behaved as composite elements until failure. Experiments indicate that the thickness of the panel affect the load carrying capacity of the concrete sandwich panel significantly. The load-deflection curves of the panels determined using numerical studies are comparable to that of the experimental results.
\end{abstract}

\section{KEYWORDS Precast, Sandwich Panels, Light-Weight Panels, Expanded Polystyrene, Self Compacting Concrete}

\section{INTRODUCTION}

Precast concrete structural elements are manufactured under controlled factory conditions and therefore concrete structural elements with good precision in geometry and finishing can be manufactured. Background information on precast technology can be found in the literature [1-3]. Precast concrete elements besides being structurally and economically efficient [4], also have social and environmental benefits [5]. Precast structural elements if light-weighted also have advantages such as (i) less attraction of seismic forces, (ii) ease of handling and transportation and (iii) cost effective. Light-weight concrete sandwich panels produced by replacing core concrete using lesser dense material consist of two skins of concrete called wythe, one on either side of the core. Welded wire mesh or conventional steel rebars may be used to reinforce the wythes. The core is made of material that provides significant thermal and sound insulation. In this study, EPS (Expanded PolyStyrene) is used as the core. In order to achieve composite action of the panel under flexural load shear transfer between the two wythes is ensured by using shear connectors that connect the two wythes.

Experimental studies on the behavior of light-weight concrete sandwich panels under different load conditions can be found in the literature [6-18] which have proved the feasibility of using these panels for floors, roofs and walls of the buildings. Nevertheless, it is noted that in the literature no studies are found reported on the flexural behavior of light-weight concrete sandwich panels with wires as shear connectors. In this paper the results of the experimental study carried out to determine the flexural behavior of prototype precast light-weight concrete sandwich panels with wires as shear connectors under four-point bending are presented. Two prototype panels are tested in the present study to study the effect of percentage of reinforcement in wythes and the total thickness of the panel, both of which are directly proportional to the moment carrying capacity, ultimate load carrying capacity and the flexural behavior of light-weight concrete sandwich panel. The variation in the thickness of the panel is achieved by using different core thicknesses. The paper is organized as follows. Section 2 presents the materials used and casting of the panels, Section 3 presents the test set-up and the instrumentation details, Section 4 presents the results and discussions and Section 5 presents summary and conclusions.

\section{EXPERIMENTAL STUDY}

\subsection{MATERIALS USED}

Two numbers of prototype precast light-weight concrete sandwich panels with different thicknesses $(100 \mathrm{~mm}$ and $150 \mathrm{~mm})$ are tested to failure. The panel with thickness $150 \mathrm{~mm}$ is named FA and the one with $100 \mathrm{~mm}$ is named FB. The length and breadth of a panel is $1200 \times 3000 \mathrm{~mm}$. The schematic sketch of the components of panels considered is shown in Fig. 1. Welded wire mesh of grid size 50x50mm was used for reinforcing concrete wythes. The two meshes were connected at equal intervals using shear connectors inclined at an angle of $45^{\circ}$. The wires of the mesh and the 
shear connectors were nearly $2.2 \mathrm{~mm}$ in dia. The average tensile strength of the steel wire as supplied by the manufactures is $651.64 \mathrm{MPa}$. Self Compacting Concrete (SCC) was used for making the wythes. The mix proportion for SCC was arrived based on the guidelines of $\mathrm{ACI}^{19}$ and it is 1:1.89:2.34:0.3:0.41:0.6\% in the order of Cement, Coarse aggregate, Fine aggregate, Ground Granulated Blast Furnace Slag (GGBFS), Water and Superplasticizer (by weight of binder content). It was ensured that the SCC mixture considered satisfies the recommended $^{6}$ minimum requirements. Coarse aggregates passing $10 \mathrm{~mm}$ sieve were used in SCC. Same mix proportion was used for casting both panels. The average compressive and flexural tensile strengths of SCC were found to be $45.97 \mathrm{MPa}$ and $4.34 \mathrm{MPa}$, respectively. Table 1 gives the details of the prototype precast light-weight concrete sandwich panels considered for the present experimental study.

\subsection{CASTING OF PANELS}

The sequence of casting the panel is shown in Fig. 2. A steel mould of size $1200 \times 3000 \mathrm{~mm}$ was placed on a level surface and SCC was poured to a depth of $25 \mathrm{~mm}$ to form bottom wythe. EPS with wire mesh was placed over the concrete. SCC was then poured on the EPS to form top wythe of $25 \mathrm{~mm}$ thickness. Stiffening concrete beams were provided along the supporting edges to avoid failure due to local crushing of concrete. The panels manufactured were cured for 28 days. The manufacturing methods reported in the literature [6-18] involved either plastering on the EPS panel using cement mortar or placing normal concrete on the EPS panel and vibrating for achieving better compaction of concrete. These methods require skilled labor and sufficient time for casting and finishing the panel. The method of manufacturing adopted in this paper does not require highly skilled labor. Time taken for casting a panel is 30 minutes. This method of manufacturing light-weight concrete sandwich panel using ready-made EPS panel and SCC is expected to suit mass production of the panels.

\subsection{TEST SET-UP AND INSTRUMENTATION}

The panels manufactured were tested under four-point bending. This type of loading was chosen because of constant bending moment being developed between the loading points. Displacement controlled loading was applied until the panels failed. One edge of the panel was supported by a hinge and the other was supported by a roller. It was ensured that the supports were provided on the stiffening beams. Linear Voltage Displacement Transducers (LVDTs) with $50 \mathrm{~mm}$ range were used to measure the deflections of the panels. Strain gauges with gauge length of $2 \mathrm{~mm}$ and $30 \mathrm{~mm}$ were used to measure the strains on the wires and concrete surface, respectively. Schematic sketch of the test set-up and the locations of the LVDTs are shown in Fig. 3. Photograph of a panel ready for testing is shown in Fig. 4.

\section{NUMERICAL STUDY}

Numerical studies were carried out in the general purpose finite element software ABAQUS to model the nonlinear behavior of the concrete sandwich panels. In ABAQUS, the behavior of concrete was modeled using the material model concrete damaged plasticity. In this model, concrete is assumed to be isotropic in elastic and inelastic regime both in compression and tension. To describe the behavior of concrete under compression, stress-strain curve for concrete under uni-axial compression is constructed by using the model proposed by Saenz [24]. The Young's modulus of concrete was determined using the empirical relation given in IS 456:2000 [25].

$\mathrm{E}=5000 \sqrt{ } \mathrm{f}_{\mathrm{ck}}=5000 \sqrt{ } 45=33541 \mathrm{MPa}$.

Under tension, the concrete is assumed to behave linearly elastic until tensile strength of the concrete. The tensile strength of concrete is chosen by inverse analysis so as to predict the load-deflection curves comparable to that of experimental results. The post-peak behavior of concrete under tension is specified using fracture energy method. The fracture energy of the concrete was determined using the relation given in CEB-FIB Model Code [26], which is a function of concrete cylinder strength $\left(f_{\mathrm{cm}}\right)$. The cube strength is converted to equivalent cylinder strength by multiplying a factor of 0.8 .

Fracture energy, $\mathrm{G}_{\mathrm{f}}=73 \mathrm{f}_{\mathrm{cm}}{ }^{0.18}=73 \mathrm{x}(0.8 \mathrm{x} 45)^{0.18}=139 \mathrm{~J} / \mathrm{m}^{2}$ 8 -noded linear brick and 2-noded linear truss elements were used to model the wythes and mesh reinforcements, respectively. It is assumed that there is no slip between the mesh reinforcements and the concrete and hence the bonding is assumed to be perfect. The shear connectors were modeled as springs. The slope of the load-deflection curve of the wires under uni-axial tension within elastic limit is specified as the stiffness of the spring. Considering the symmetry of the panel, one quarter of the sandwich panel is modeled. The support condition specified for the model is shown in the Fig. 5. The FE model developed in ABAQUS is shown in Fig. 6.

\section{RESULTS AND DISCUSSIONS}

The picture of a panel tested is shown in Fig. 7. No separation of wythes was observed for both panels tested and hence, it can be concluded that both panels behaved as composite elements until failure. For both panels first crack appeared in the tensile region of the panel between one of the loading points and the nearest support.

Very few flexural cracks were seen in the maximum bending moment region of panel FB. Panel FA deformed extensively which resulted in relatively more numbers of flexural cracks in the maximum bending moment region. It is noted that, for both panels first crack occurred in the region between one of the loading points and the nearest support (and not in the maximum bending moment region). The formation and propagation of first crack in all the panels is thus attributed to mixed-mode fracture, i.e., combined effect of tensile stress (due to flexure) and shear stress. The load-deflection curves obtained from the experiments and numerical studies are shown in the Fig. 8.

From Fig. 8 it is observed that, the panels FA and FB behave 
linearly upto loads $9.71 \mathrm{kN}$ and $5.48 \mathrm{kN}$, respectively. The ultimate failure load of the panel FA is almost $200 \%$ greater than that of the panel FB. This is due to the higher thickness of the panel (and hence larger lever arm). It is observed that, the load-deflection curves obtained using the numerical models are in close agreement with the experimental results. The distribution of inelastic strain (along the span) of the panel is shown in the Figs. 9 and 10.

From Figs. 9 and 10, it can be observed that, as expected, for both panels strains are higher in the maximum bending moment region. For the panel FB the strain in the bottom wythe under (almost) the loading point is observed to be larger comparative to any other location. For both the panels, the inelastic strain is seen to be larger between the points at which the springs are connected to the bottom wythe.

\section{SUMMARY AND CONCLUSIONS}

The results of the experiments carried out to study the flexural behaviour of precast light-weight concrete sandwich panel are presented in this paper. It is found from the experiments that the thickness of the panel have profound effect on the load carrying capacity of the panel. Numerical study indicates that, the model developed is capable of predicting the load-deflection curves comparable to that determined experimentally. Carrying out further experimental and numerical study with different mesh sizes, with additional conventional steel rebars and thickness of the panel may form future area of the research towards developing design guidelines.

\section{ACKNOWLEDGEMENT}

This paper is published with the permission of the Director, CSIR-SERC.

\section{REFERENCES}

[1]. Alfred Yee A. Prestressed concrete for buildings. PCI J 1976;24(5):112-157.

[2]. Alfred Yee A, Kim Chang Nai. One hundred Washington square: Structural Design and Construction. PCI J 1984;29(1):24-48.

[3]. Alfred Yee A. Design considerations for precast prestressed concrete building structures in seismic areas. PCI J 1991;36(3):40-55.

[4]. Alfred Yee A. Social and environmental benefits of precast/prestressed concrete construction. PCI J 2001;46(3):14-19.

[5]. Alfred Yee A. Structural and economic benefits of precast/prestressed concrete construction". PCI J 2001;46(4):34-42.

[6]. Benayoune, A., Samad, A.A.A., Trikha, D.N., Abang Ali, A.A., Ellinna, S.H.M. (2008). "Flexural behavior of pre-cast concrete sandwich composite panel Experimental and theoretical investigations". J Constr Build Mater 2008;22:580-592.

[7]. Bush, T.D., Stine, G.L. Flexural behaviour of composite precast concrete sandwich panels with continuous truss connectors. PCI J 1994;39(2):11221.

[8]. Bush, T.D., Wu, Z. Flexural analysis of prestressed concrete sandwich panels with truss connectors. PCI J 1998;43(5):76-86.

[9]. Carbonari, G., Cansario, S.H.P., Cavalaro, M.M., Aguado, A. Flexural behaviour of light-weight sandwich panels composed by concrete and EPS. J Constr Build Mater 2012;35:792-799.

[10]. Einea, A., Salmon, D.C., Tadros, M.K., Culp, T. A new structurally and thermally efficient precast sandwich panel system. PCI J 1994; 39(4): 90-101.

[11]. Einea, A., Salmon, D.C., Tadros, M.K., Culp, T. Partially composite sandwich panel deflection". J Struct Eng ASCE 1995;121(4):778-83.

[12]. Gara, F., Ragni, L., Roia, D., Dezi, L. Experimental tests and numerical analysis of floor sandwich panels. Eng Struct 2012;36:258-260.

[13]. Henin, E., Marcous, G., Tadros, M.K. Precast/Prestressed concrete sandwich panels for thermally efficient floor/roof applications. Pract Period Struct Des Constr 2014:1-12.

[14]. Salmon, D.C., Einea, A., Tadros, M.K., Culp, T.D. Full scale testing of precast concrete sandwich panels". J Struct ACI 1997;354-362.

[15]. Yardim, Y., Waleed, A.M.T., Jaafar, M.S., Laseima, S. AAC-concrete light weight precast composite floor slab. J Constr Build Mater 2013;40:405-410.

[16]. Benayoune, A., Samad, A.A.A., Trikha, D.N., Abang Ali, A.A., Ashrabov, A.A. Structural behaviour of eccentrically loaded precast sandwich panels. J Constr Build Mater 2006;20(9):713-724.

[17]. Benayoune, A., Samad, A.A.A., Abang Ali, A.A., Trikha, D.N. Response of pre-cast reinforced composite sandwich panels to axial loading. J Constr Build Mater 2007;21(3):677-685.

[18]. Gara, F., Ragni, L., Roia, D., Dezi, L. Experimental tests and numerical modelling of wall sandwich panels. Eng Struct 2012;37:193-204.

[19]. ACI commitee 237. Self Consolidating Concrete. ACI 2007.

[20]. Allen, H.G. Analysis and Design of Structural Sandwich Panels. Pergamon Press 1968, Oxford.

[21]. Indian Standard IS 516:1959. Methods of tests for strength of concrete, Bureau of Indian Standards 2002.

[22]. Park, R., Paulay, T. Reinforced Concrete Structures, John Wiley \& Sons Inc., 1975.

[23]. Carmona, J.R., Ruiz, G., Viso, J.R. Mixed-mode crack propagation through reinforced concrete. Eng Frac Mech 2007;74:2788-2809.

[24]. Saenz, L.P. Discussion of "Equation for stress-strain curve of concrete" by Desayi P, Krishnan S. ACI Journal 1964;61:1229-35.

[25]. Indian Standard IS 456:2000. Plain and Reinforced Concrete - Code of Practice, Bureau of Indian Standards 2005.

[26]. The Fib Model Code for concrete structures, Ernst \& Sohn, 2010. 
Table 1 Details of the sandwich panels considered

\begin{tabular}{|l|l|l|l|l|}
\hline \multirow{2}{*}{ Specimen } & \multirow{2}{*}{ Mesh size (mm) } & Thickness $(\mathbf{m m})$ & \multicolumn{2}{l|}{} \\
\cline { 3 - 5 } & & Wythe & EPS & Total \\
\hline FA & $50 \times 50$ & 25 & 100 & 150 \\
\hline FB & $50 \times 50$ & 25 & 50 & 100 \\
\hline
\end{tabular}
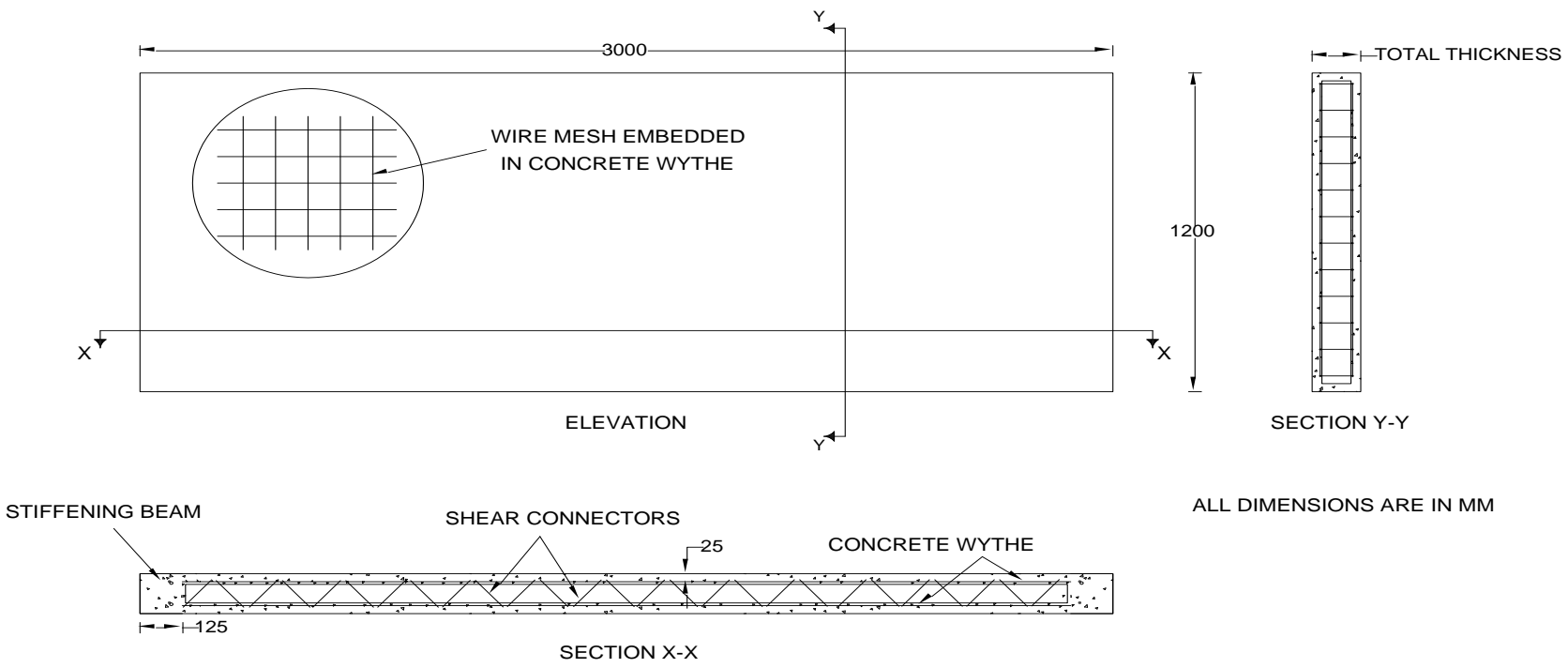

ALL DIMENSIONS ARE IN MM

Fig. 1 Schematic sketch of sandwich panel
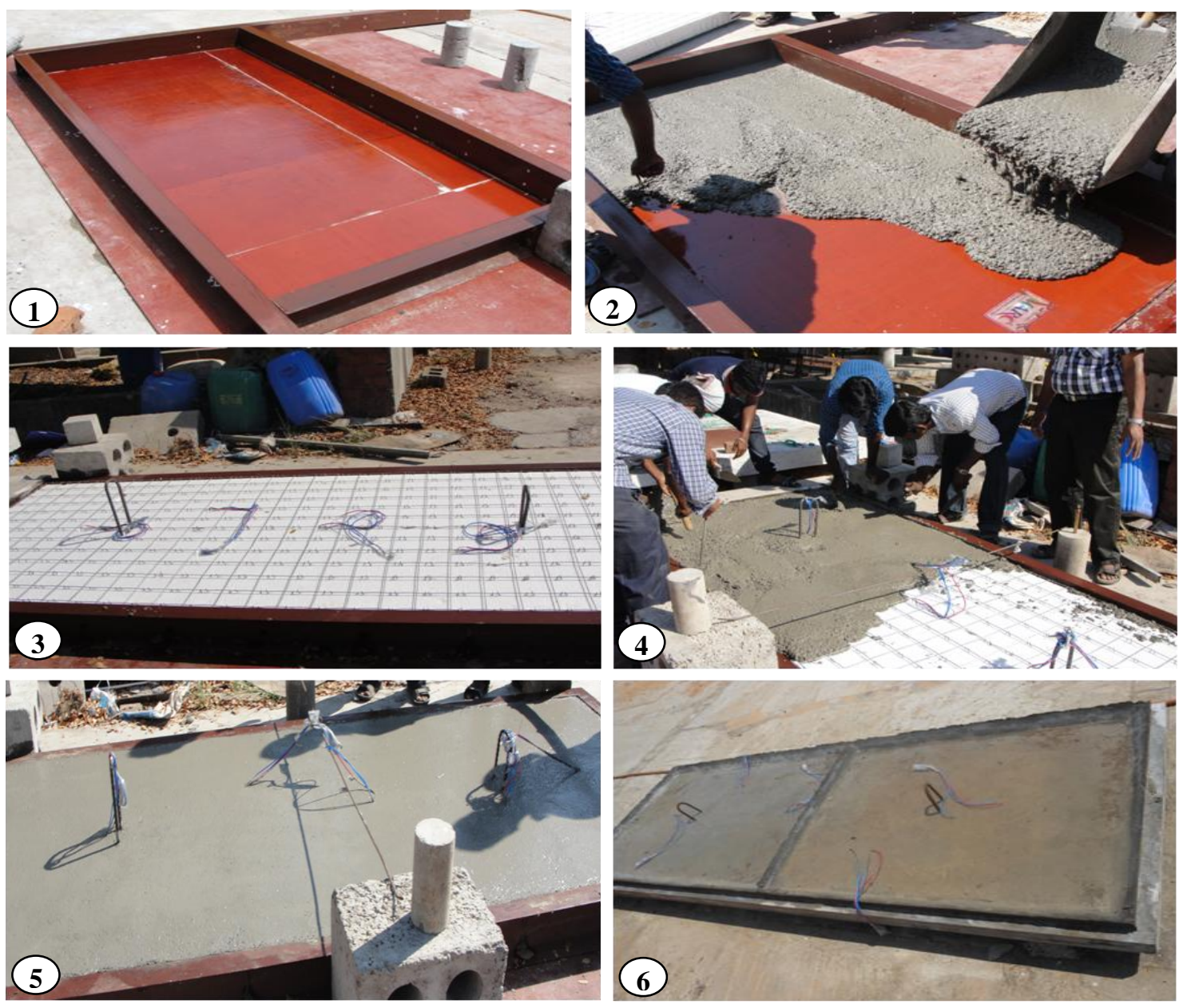

Fig. 2 Sequence of casting a panel 


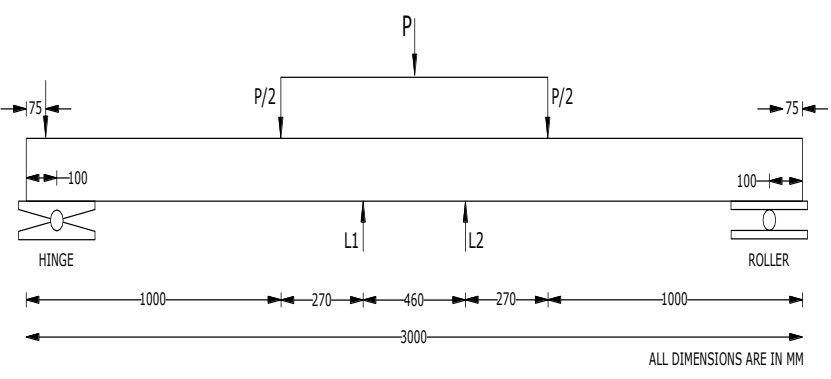

Fig. 3 Schematic test set-up and locations of LVDTs

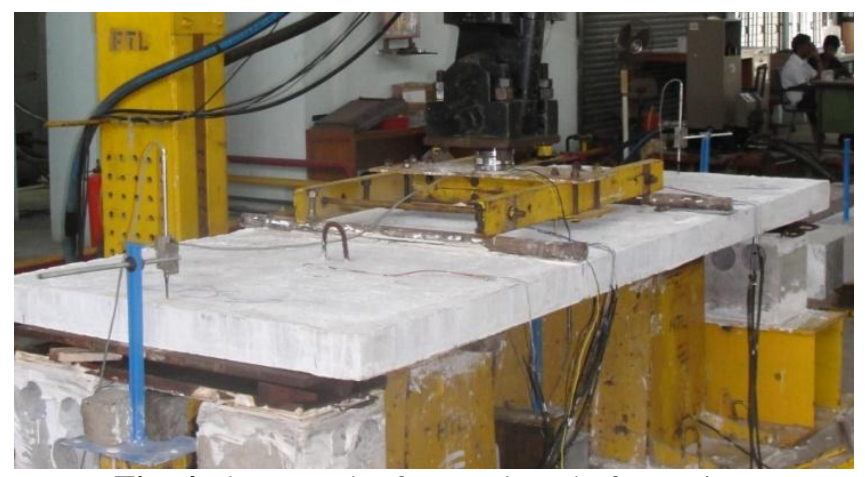

Fig. 4 Photograph of a panel ready for testing

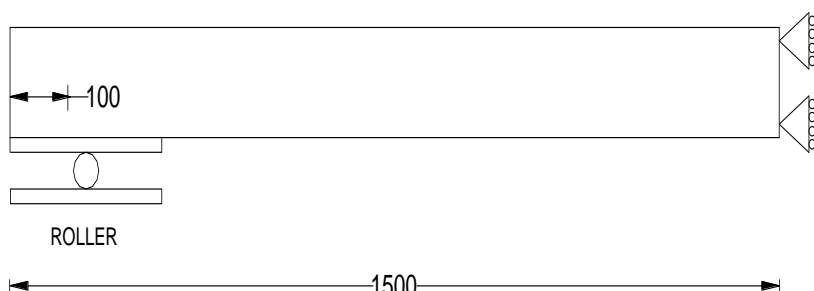

Fig. 5 Support condition assumed in FE model

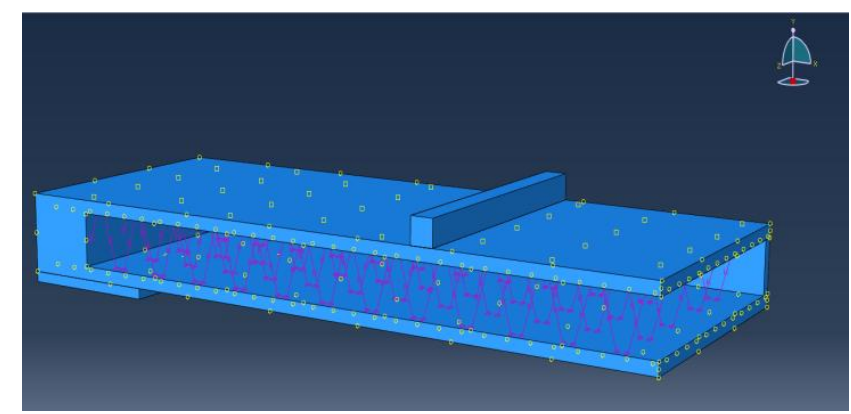

Fig. 6 FE model developed in ABAQUS

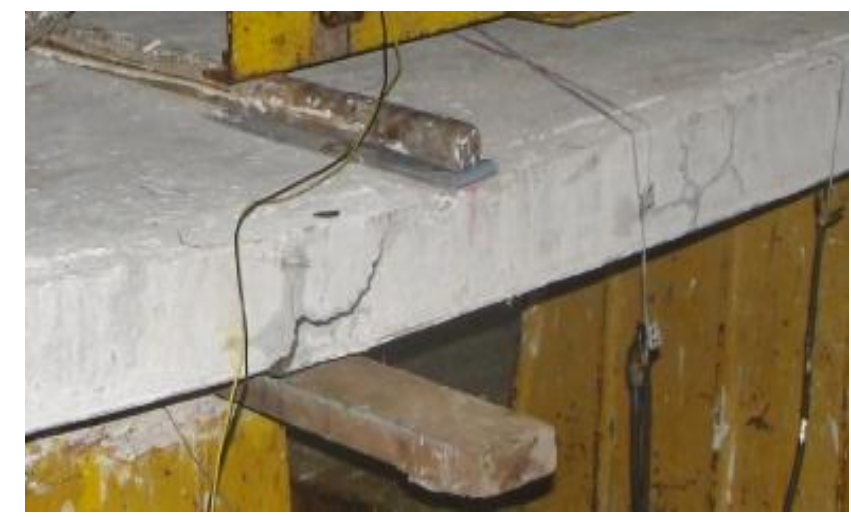

Fig. 7 Photograph of tested panel FB

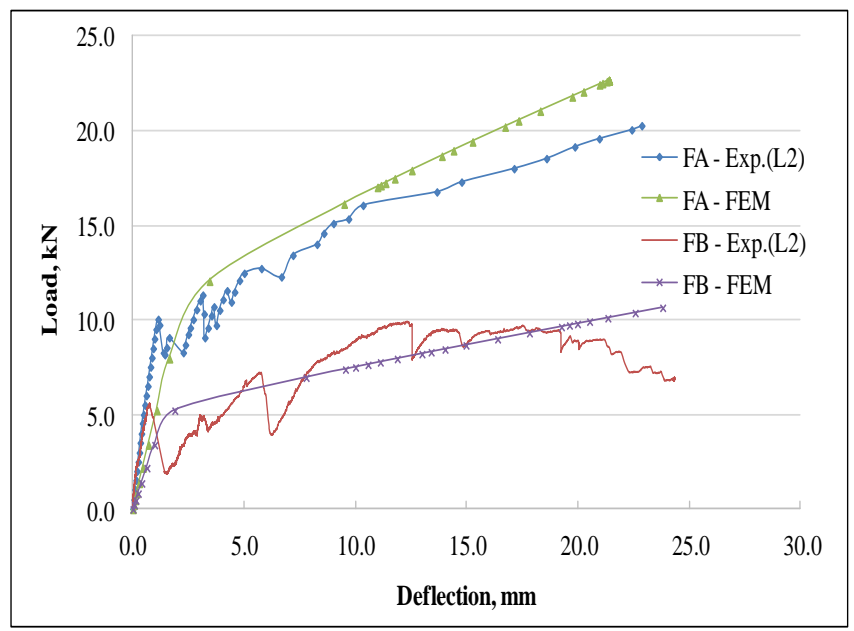

Fig. 8 Experimental and FE load-deflection curves

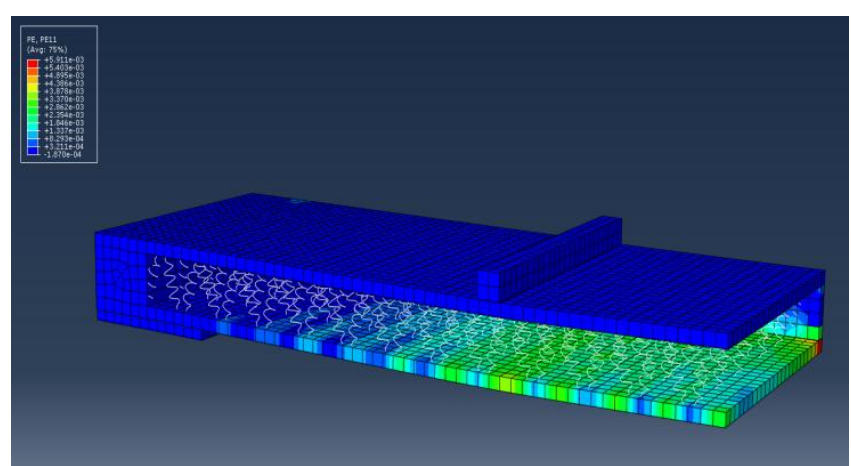

Fig. 9 Inelastic strain distribution along the span of panel FA

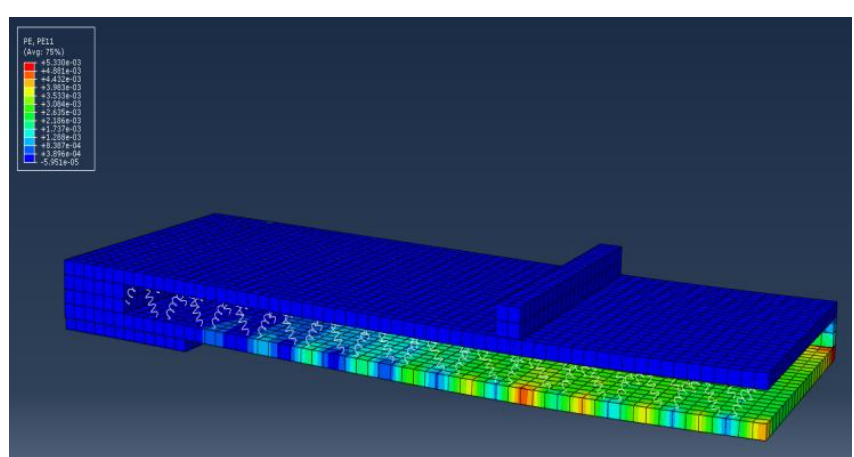

Fig. 10 Inelastic strain distribution along the span of panel FB 